\title{
\#Bibliotheca 002.1: Matematikçi Gibi Düşünmek I. Kısım: Matematikçiler İçin Çalışma Becerileri
}

Matematik ve Matematik Mühendisliği Topluluğu ${ }^{1}$

${ }^{1}$ Affiliation not available

November 26, 2020

Bu içeriğimizde Kevin Houston tarafından yazılmış ve Türkçeye Mehmet Terziler ile Tahsin Öner tarafından çevrilmiş olan Matematikçi Gibi Düşünmek adlı kitabın "Matematikçiler İcin Çalışma Becerileri" kısmının özeti yer alıyor. Lisans matematiği için bir kılavuz olarak belirtilen bu kitaptaki her başliğın temel kısımlarını kendi görsellerimizle derledik.

UYARI Bu özete dair tanım, teorem ve açıklamaların detayları halihazırda kitapta bulunmaktadır. Bu nedenle konuları daha detaylı öğrenmek, örneklerle pekiştirmek ve konularla ilgili alıştırma yapmak için lütfen kitaba başvurunuz.

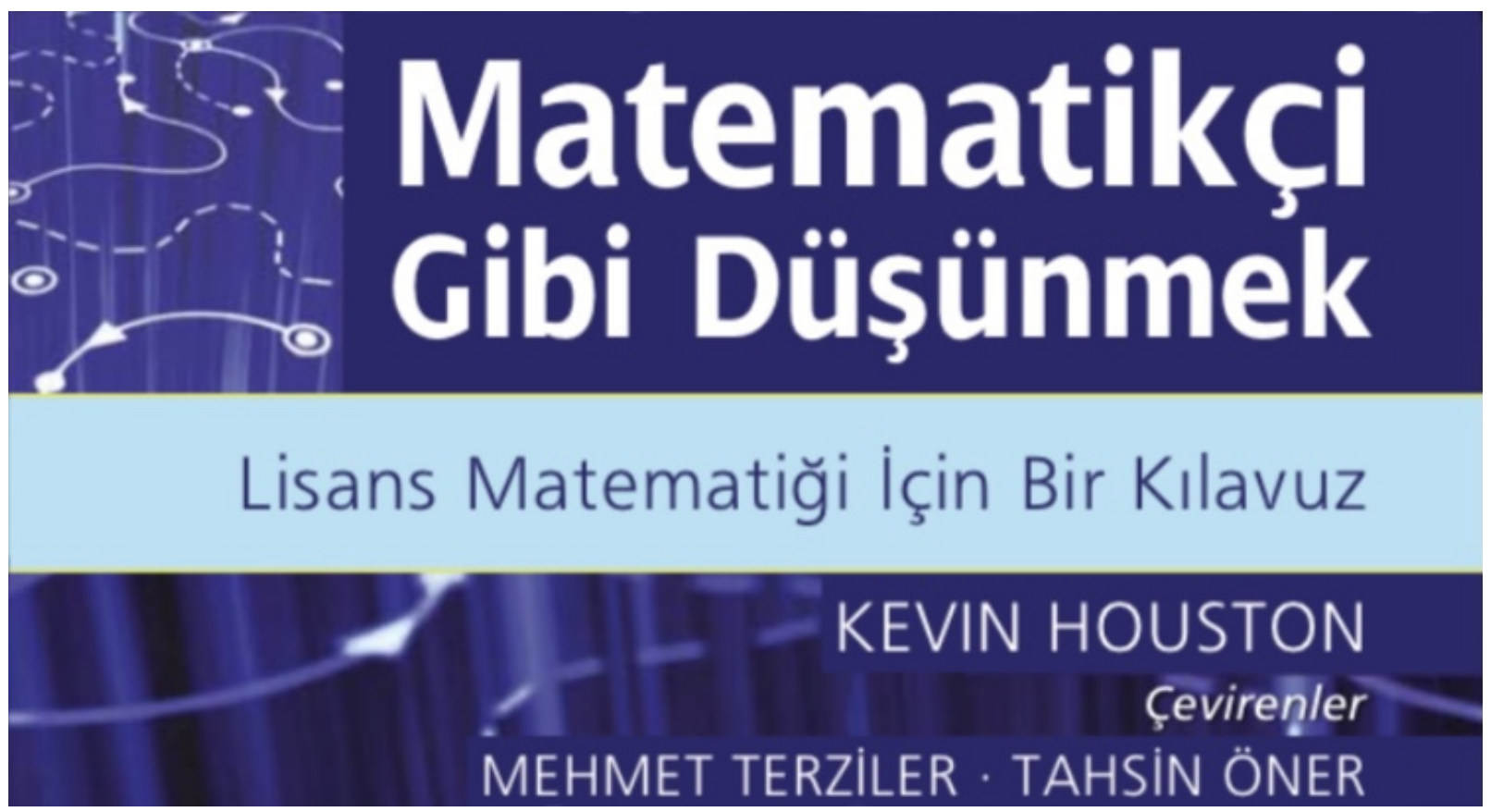

Figure 1: Matematikçi Gibi Düşünmek: Lisans Matematiği İçin Bir Kılavuz

Yazı İçeriği:

Kümeler ve Fonksiyonlar

Matematiği Okuma 


\title{
Matematiği Yazma I \\ Matematiği Yazma II \\ Problemler Nasıl Çözülür \\ Referanslar
}

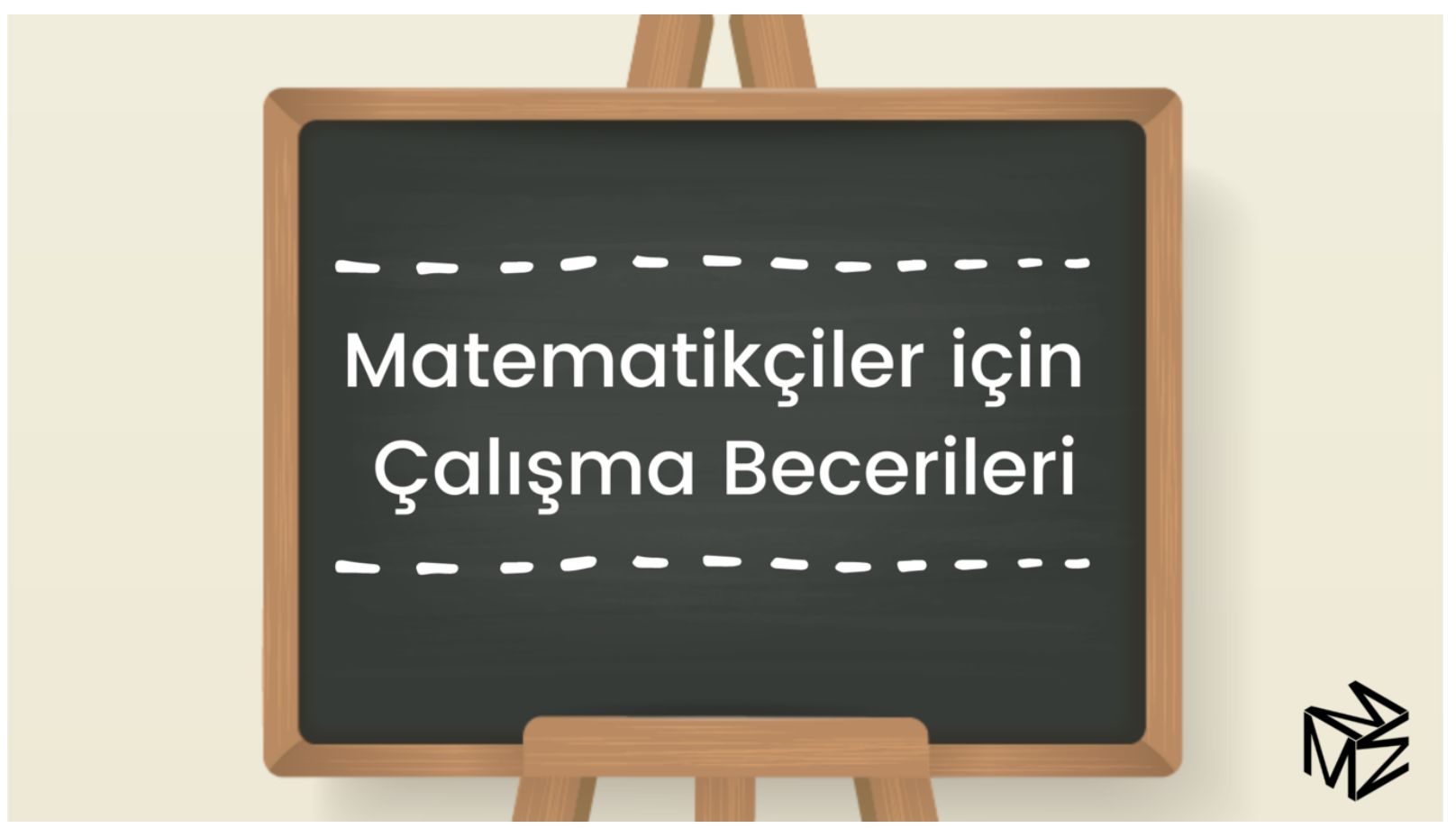

Figure 2: Matematikçi Gibi Düşünmek kitabının birinci bölümü, matematikçiler için önemli olan temel çalı̧̧ma becerilerini konu almaktadır.

\section{Bölüm: Kümeler ve Fonksiyonlar}

\begin{abstract}
"Everything starts somewhere, although many physicists disagree."
"Pek çok fizikçi katılmıyor olsa da, her şey bir yerden başlar."
\end{abstract}

\section{Terry Pratchett, Hogfather}

Bir matematikçi gibi düşünmek, üzerinde düşünülecek bir matematik gerektirir. Bu matematiğe sahip olduğumuza göre, bu bölüm kümeler ve fonksiyonlarla başlıyor. Kümeler ve fonksiyonlar, en temel matematiksel nesnelerdir, ama amaçlarımız için yeterince sorgulamaya sahiptirler.

Yüksek matematiğin tamamına yakın kısmı kümeler ve fonksiyonlar üzerinedir. Örneğin kalkülüs, gerçel sayılar kümesinden gerçel sayılar kümesine türevlenebilir özellikli fonksiyonların çalışmasıdır. Bu nedenle "Matematiğin yapı taşları kümeler ve fonksiyonlardır." diyebiliriz. 


\section{Kümeler}

Tanım: Bir küme, iyi-tanıml nesneler topluluğudur. ${ }^{1}$

Kümedeki nesnelere kümenin elemanları ya da ögeleri denir. Eğer x, X kümesinin bir elemanı ise o zaman " $x$ [?] $X$ " yazıyor ve " $x, X^{\prime}$ 'in elemanıdır (ögesidir) " ya da " $x, X$ 'dedir. - olarak okuyoruz. Eğer $\mathrm{x}, \mathrm{X}$ kümesinin bir elemanı değilse " $x$ [?] $X$ " yazıyoruz.

1. Kümenin gerçek matematiksel tanımı çok daha karmaşıktır. Bu tanım sezgiseldir ve bize fazla sorun yaratmayacaktır.

\section{Bazı İlginç Sayı Kümeleri}

- Doğal Sayllar

Doğal sayıların kümesi $\{1,2,3,4, \ldots 0\}$ 'dir ve N ile gösterilir. Noktalar, sonsuza kadar devam edebileceğimiz anlamina gelir.

Bazı matematikçiler, özellikle lojikçiler, 0'ı doğal sayıların içine katarlar. Diğerleri ise doğal sayıların sayma sayıları olduğunu ve 0'dan başlayarak saymadığınızı söylerler. Öte yandan 0 [?] N alırsak bazı teoremler daha iyi ifade edilir. Bu tartışma negatif olmayan tamsayılarla ya da pozitif tamsayılarla çalışıldığı belirtilirse tatliya bağlanabilir.

- Tam Saylar

Tam saylların kümesi $\{\ldots,-4,-3,-2,-1,0,1,2,3,4, \ldots\}$ 'dir ve $\mathrm{Z}$ ile gösterilir. Z sembolü, Almanca'da sayı anlamma gelen Zahlen sözcügünden gelir. Tüm doğal sayılar tam sayıdır.

- Rasyonel Sayılar

Rasyonel sayıların kümesi tüm kesirli sayılardan oluşur ve Q ile gösterilir. Yani $p$ ve $q$ tam sayılar ve $q$ [?] 0 olmak üzere $x, p / q$ şeklinde yazılabiliyorsa $x$ [?] Q'dir. Örneğin 1/2,6/1,80/5 gibi. Ayrıca tüm tam sayılar rasyonel sayılardır çünkü $x$ [?] Z, x / 1 gibi yazılabilir.

- Gerçel Sayılar

R ile gösterilir. Gerçel sayıların katı tanımını yapmak zor olduğundan şimdilik bu sayıları ondalık temsil verilebilen herhangi bir sayı ya da sonsuz uzunluklu bir sayı doğrusu üzerinde bir nokta gibi temsil edilen bir sayı olarak kabul edelim.

Gerçel sayılar tüm rasyonel sayıları içerir. Ayrıca $\pi$ ve e de gerçel sayılardır. ${ }^{2}$ Rasyonel olamayan gerçel sayllara irrasyonel sayılar denir.

2. Bu savların kanıtı bu kitabın konusu dışındadır.

- Karmaşık Sayılar

-1'in karekökünün var olduğunu iddia ederek C ile gösterilen karmaşık sayıları tanımlayabiliriz. Karmaşık sayllar, kuramsal ve uygulamalı matematikte kullanılabilmektedir.

\section{Kümeler Üzerine Ayrıntılar}

- Boş Küme

Tanım: Hiç elemansız kümeye boş küme denir ve Ø ile gösterilir.

Matematikte en temel ve en tuhaf küme, hiç elemansız kümedir. Bu küme, bize sayma konusunda yardım eder ve matematiğin temelleri için vazgeçilmezdir.

Tanım: Elemanları aynı olan iki küme eşittir. $X$ kümesi $Y$ kümesine eşitse o zaman $X=Y$ yazılır. Değilse $X$ [?] Y yazzlır. 
Tanım: X kümesinin sonlu sayıda eleman varsa o zaman $X$ sonlu bir kümedir deriz. $X$ sonlu ise eleman sayısına X'in kardinalitesi denir ve $|X|$ ile gösterilir.

X'in sonsuz sayıda elemanı varsa o zaman X'in kardinalitesini tanımlamak zordur, çünkü sonsuzluğun farklı büyüklükleri vardır. Şimdilik sonsuz kümeler için kardinalitenin tanımsız olduğunu söyleyeceğiz.

Tanım: X'in bir küme olduğunu varsayalım. Y'nin her elemanı X'in bir elemanı ise Y kümesi X'in bir alt kümesidir ve $Y$ [?] X olarak yazllır.

UYARI Bir kümenin elemanı olmakla bir kümenin alt kümesi olmanın arasındaki farkı görmek çok önemlidir. $\mathrm{x}$ [?] $\mathrm{X}$ ise o zaman $\{\mathrm{x}\}$ [?] $\mathrm{X}$ 'dir. Genellikle $\mathrm{x}$ [?] $\mathrm{X}$ ise o zaman $\{\mathrm{x}\}$ [?] $\mathrm{X}$ 'dir. Ancak ozel orneklerde bazen $\{\mathrm{x}\}$ [?] $\mathrm{X}$ olur.

Tanım: $Y, X^{\prime}$ 'e eşit değilse X'in bir $Y$ alt kümesine X'in bir öz alt kümesi denir ve $Y$ [?] X ile gosterilir.

Kumeleri farklı bir notasyon kullanarak tanımlayabiliriz: $\{\mathrm{x} \mid \mathrm{x}, \mathrm{P}$ özelliğini sağlar. $\}$ Bazen | yerine : da konulur ve bunlar 'öyle ki' gibi okunur.

\section{Kümeler Üzerine İşlemler}

- Kümelerin Birleşimleri

Tanım: $X$ ve Y'nin iki küme olduğunu varsayalım. X ve Y'nin X[?]Y ile gösterilen birleşimi X'de ya da $Y^{\prime}$ de ya da her ikisindeki elemanlardan oluşan kümedir.

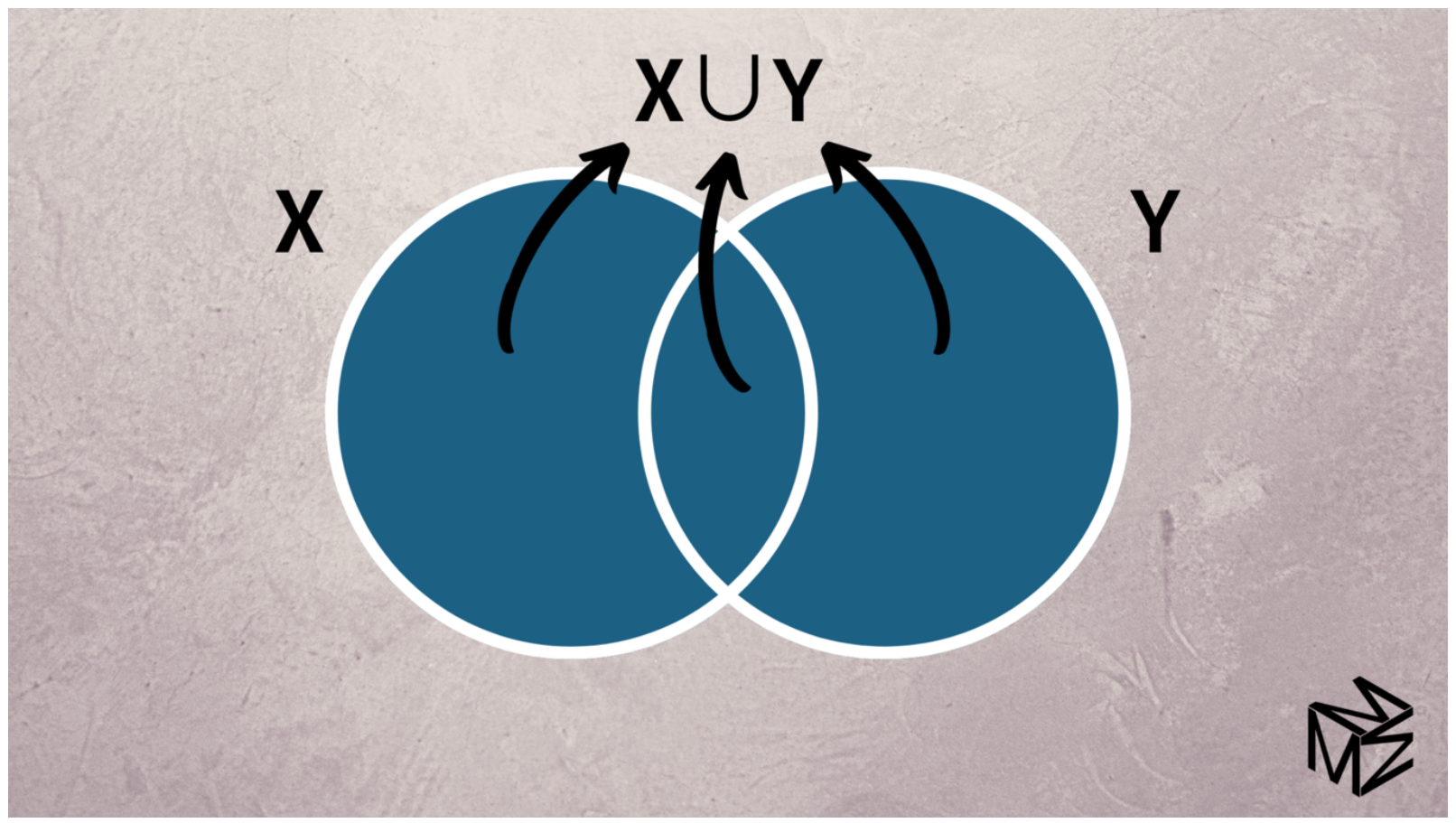

Figure 3: $\mathrm{X}$ ve $\mathrm{Y}$ kümelerinin birleşimi $\mathrm{X}[?] \mathrm{Y}$ ile gösterilir.

- Kümelerin Ara Kesitleri

Tanım: $X$ ve Y'nin iki küme olduğunu varsayalım. $X$ ve Y'nin $X$ [?] Y ile gösterilen ara kesiti X'de ve Y'de olan elemanlardan oluşan kümedir. 


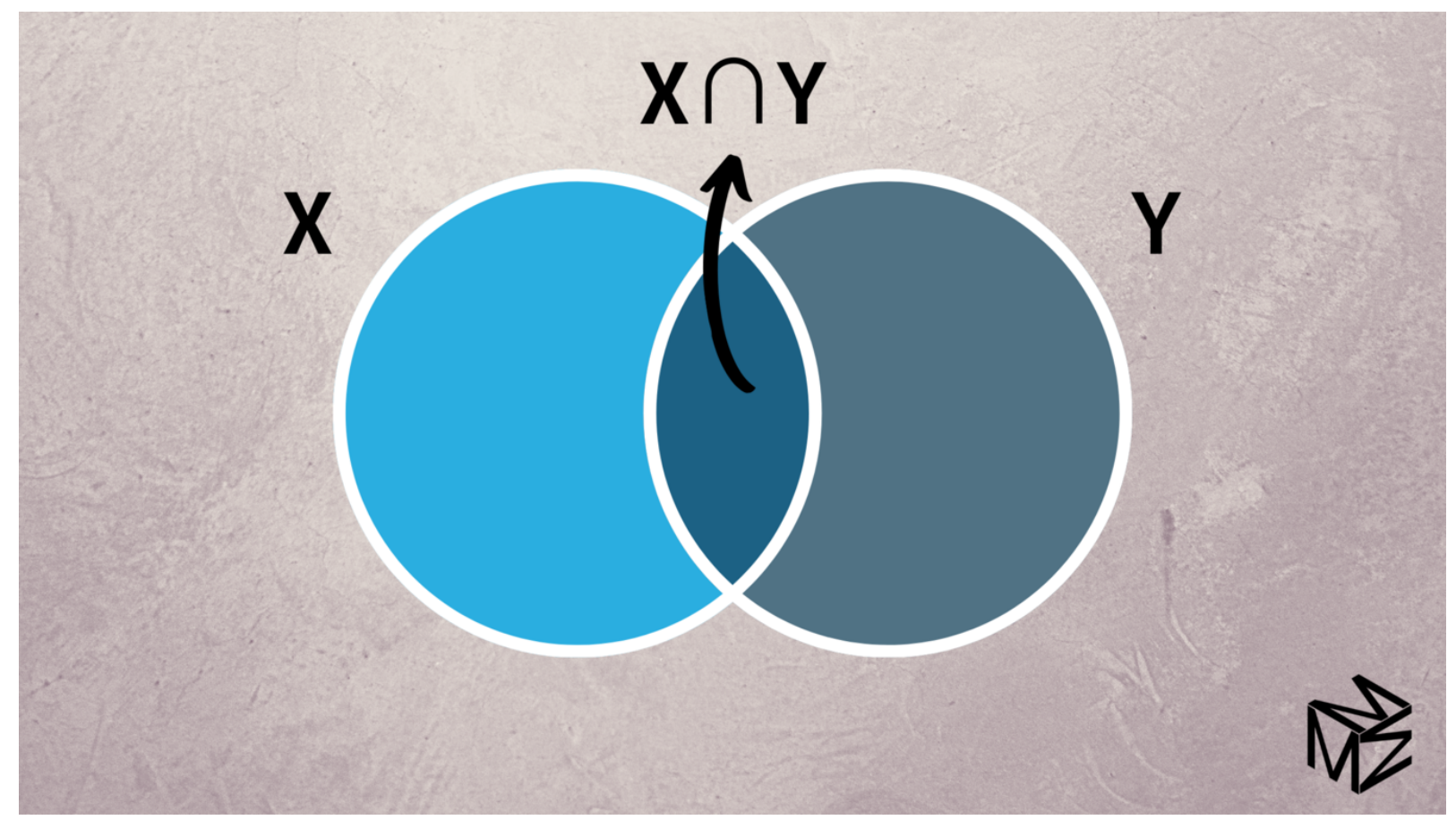

Figure 4: $\mathrm{X}$ ve $\mathrm{Y}$ kümelerinin ara kesiti $\mathrm{X}$ [?]Y ile gosterilir.

- Kumelerin Farkları

Tanım: $X$ ve Y'nin $X \backslash Y$ ile gösterilen farkı, X'de olan ama Y'de olmayan elemanların kümesidir. Ë̆er $Y$, $X^{\prime}$ 'in bir alt kümesi olarak tanımlanmıssa o zaman $X \backslash X \backslash Y$ 'ye $Y^{\prime}$ 'nin $X^{\prime}$ deki tümleyeni denir ve $Y^{c}$ ile gösterilir. 


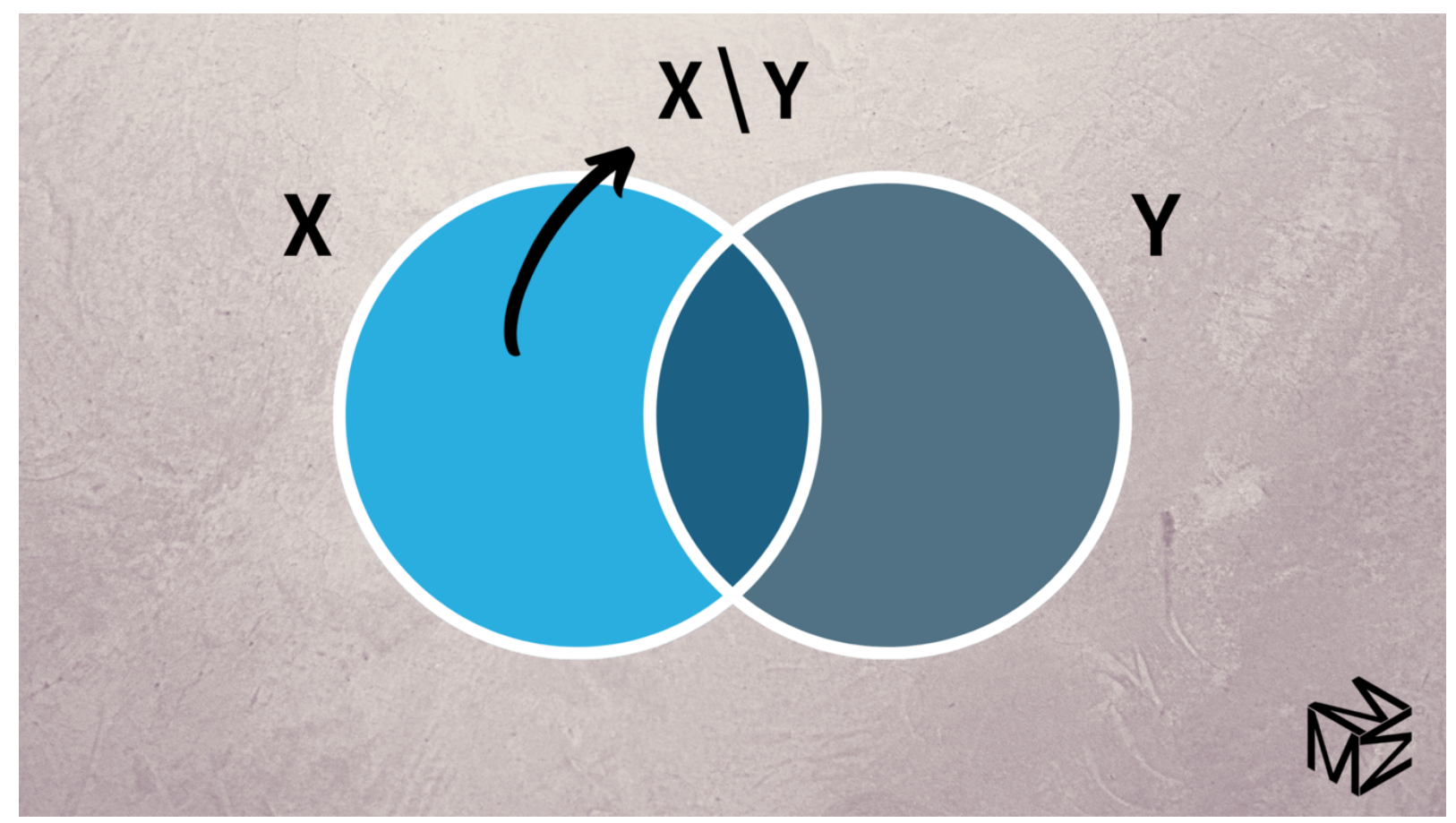

Figure 5: $\mathrm{X}$ ve $\mathrm{Y}$ kümelerinin farkı $\mathrm{X} \backslash \mathrm{Y}$ ile gösterilir.

- Kümelerin Çarpımları

Tanım: $X$ ve $Y$ iki küme olsun. $X$ ve Y'nin $X \times Y$ ile gösterilen çarpımı, x [?] X ve y [?] $\mathrm{Y}$ olmak üzere olası tüm (x,y) ikililerinin kümesidir. Yani, $X \times Y=\{(x, y) \mid x$ [?] $Y$ and y [?] $Y\}$ kumesidir.

\section{Donuşümler ve Fonksiyonlar}

Tanım: X ve Y'nin küme olduklarını varsayalım. X'den Y'ye bir fonksiyon ya da dönüşüm, kümelerin elemanları arasındaki bir bağdır. X'in her elemanı için Y'nin bir tek elemanı vardır. 


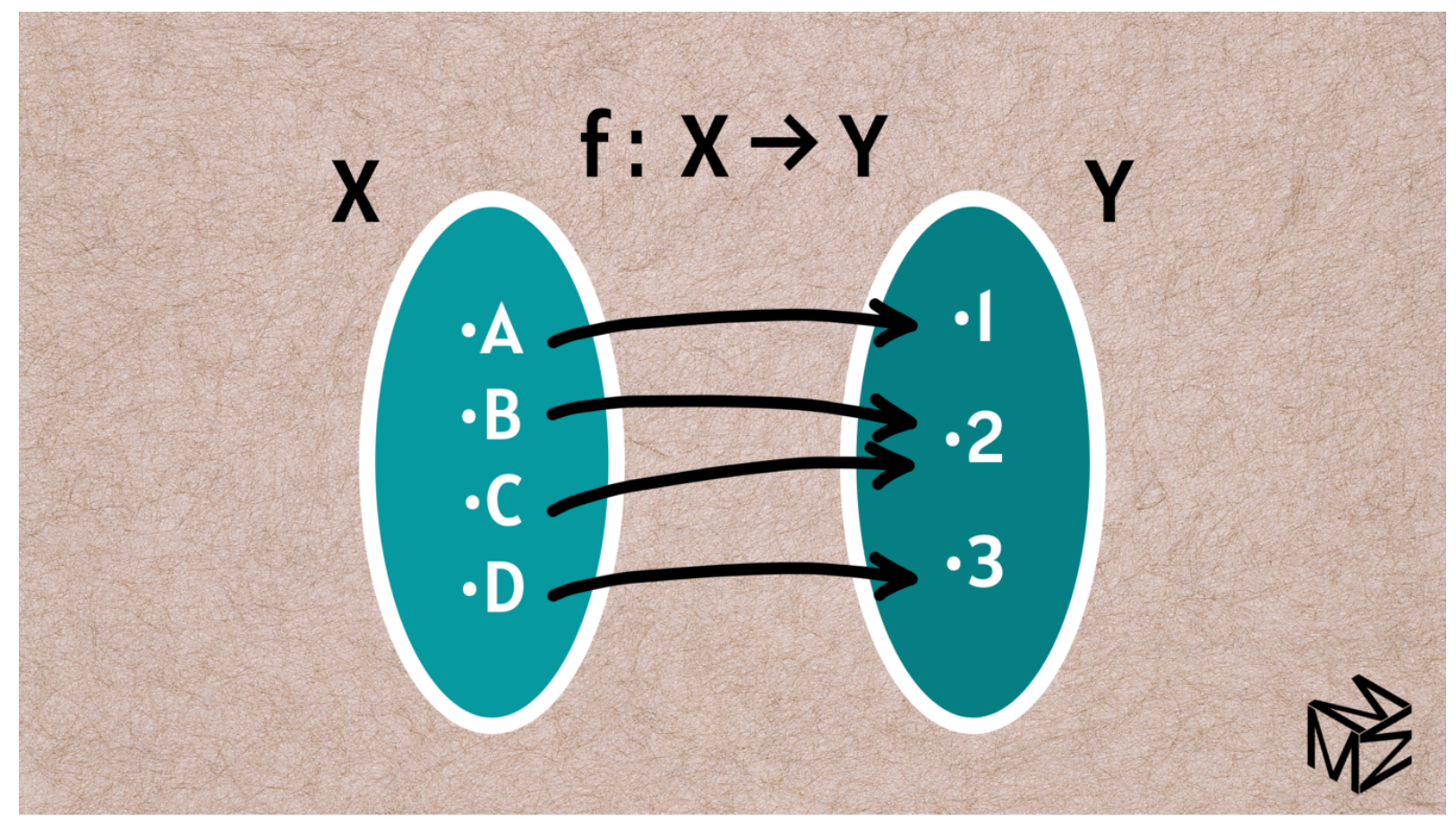

Figure 6: Fonksiyonlar, kümelerin elemanları arasındaki bir bağdır.

f, X'den Y'ye bir fonksiyon ise o zaman $\mathrm{f}: \mathrm{X}$ - Y yazllır ve x'e bağlanan Y'deki tek eleman $\mathrm{f}(\mathrm{x})$ olarak gösterilir. Bu elemana $\mathrm{x}$ 'in $\mathbf{f}$ altındaki değeri ya da f'in bir değeri denir. X kümesine f'in tanım kümesi, Y'ye ise f'nin değer kümesi denir.

\section{Özet}

- Bir küme, iyi-tanımlı nesneler topluluğudur.

- Boş kümenin hiç elemanı yoktur.

- Sonlu bir kümenin kardinalitesi kümenin eleman sayısıdır.

- Y'nin her elemanı X'de ise Y kümesi X'in bir alt kümesidir.

- X'in bir Y alt kümesi X'e eşit değilse bir öz alt kümesidir.

- X ve Y'nin birleşimi, X'de ya da Y'deki elemanların topluluğudur.

- $X$ ve Y'nin arakesiti, X'de ve Y'deki elemanlarm topluluğudur.

- $\mathrm{X}$ ve Y'nin çarpımı, $\mathrm{x}$ [?] $\mathrm{X}$ ve y [?] Y olmak üzere tüm $(\mathrm{x}, \mathrm{y})$ ikililerinin kümesidir.

- Bir fonksiyon, bir kümenin elemanlarını bir diğerine atar. 


\section{Bölüm: Matematiği Okuma}

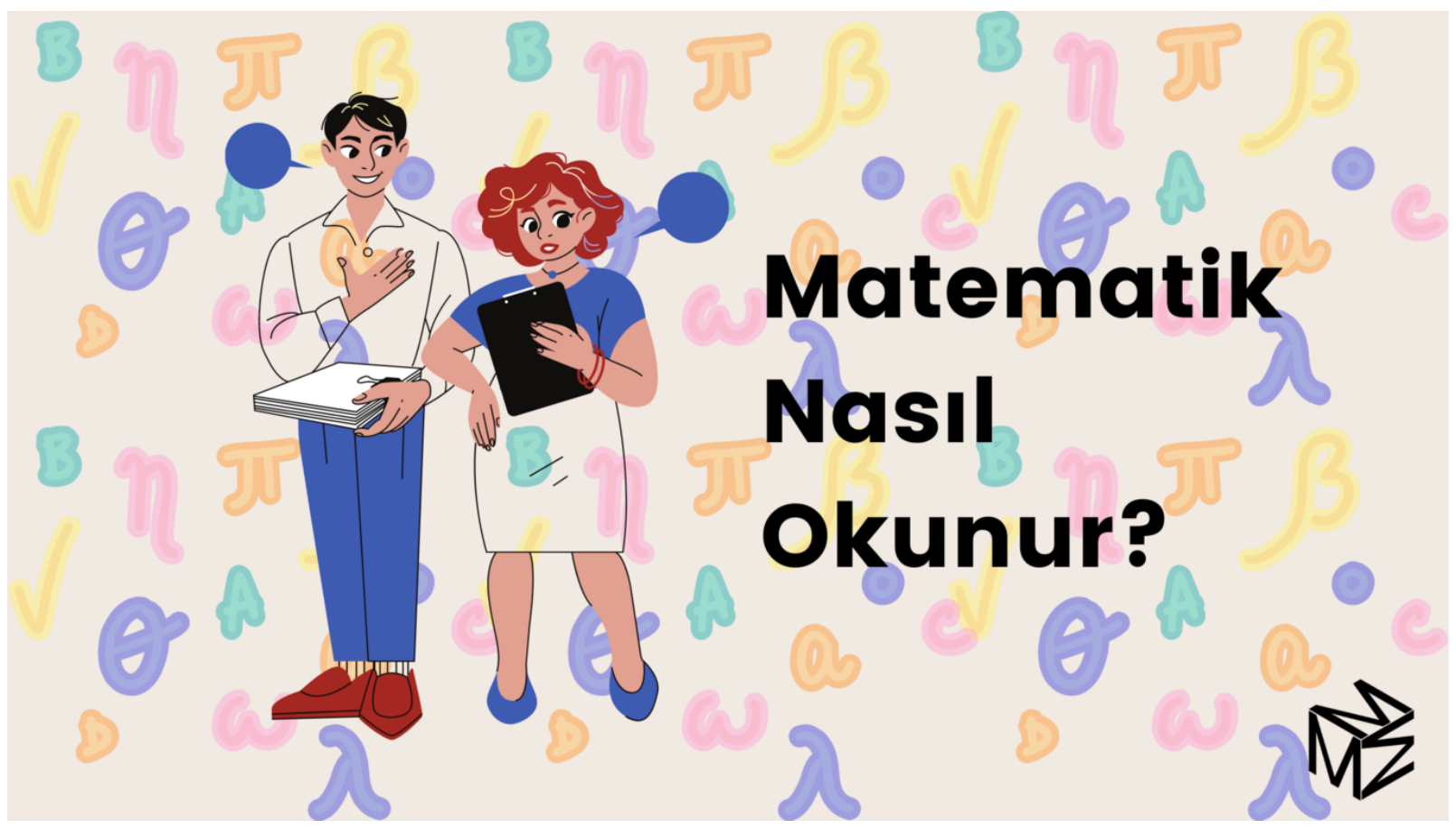

Figure 7: Matematik nasıl okunur?

"Don't believe everything you read."

"Okuduğunuz her şeye inanmayın."

\section{Anonim}

Aşağıdaki tavsiyeler sadece kitaplara değil, ders notları ve web sayfalarına yöneliktir.

\section{Temel Okuma Önerileri}

- Bir amaçla okuyun.

- Etkili okuyun. Elinizde kağıt kalem bulunsun.

- Sira halinde okumayabilirsiniz ancak düzenli okuyun.

- Sorular sorun.

- Tanımları, teoremleri ve örnekleri önce okuyun. Kanıtlar sonra gelebilir.

- Formülleri vs. uygulayarak konunun doğruluğunu kontrol edin.

- Alıştırmaları ve problemleri yapın.

- Takıldıysanız ilerleyin.

- Bir özet yazın.

- İyi düsünün, ne öğrendiniz? 


\section{Bölüm: Matematiği Yazma I}

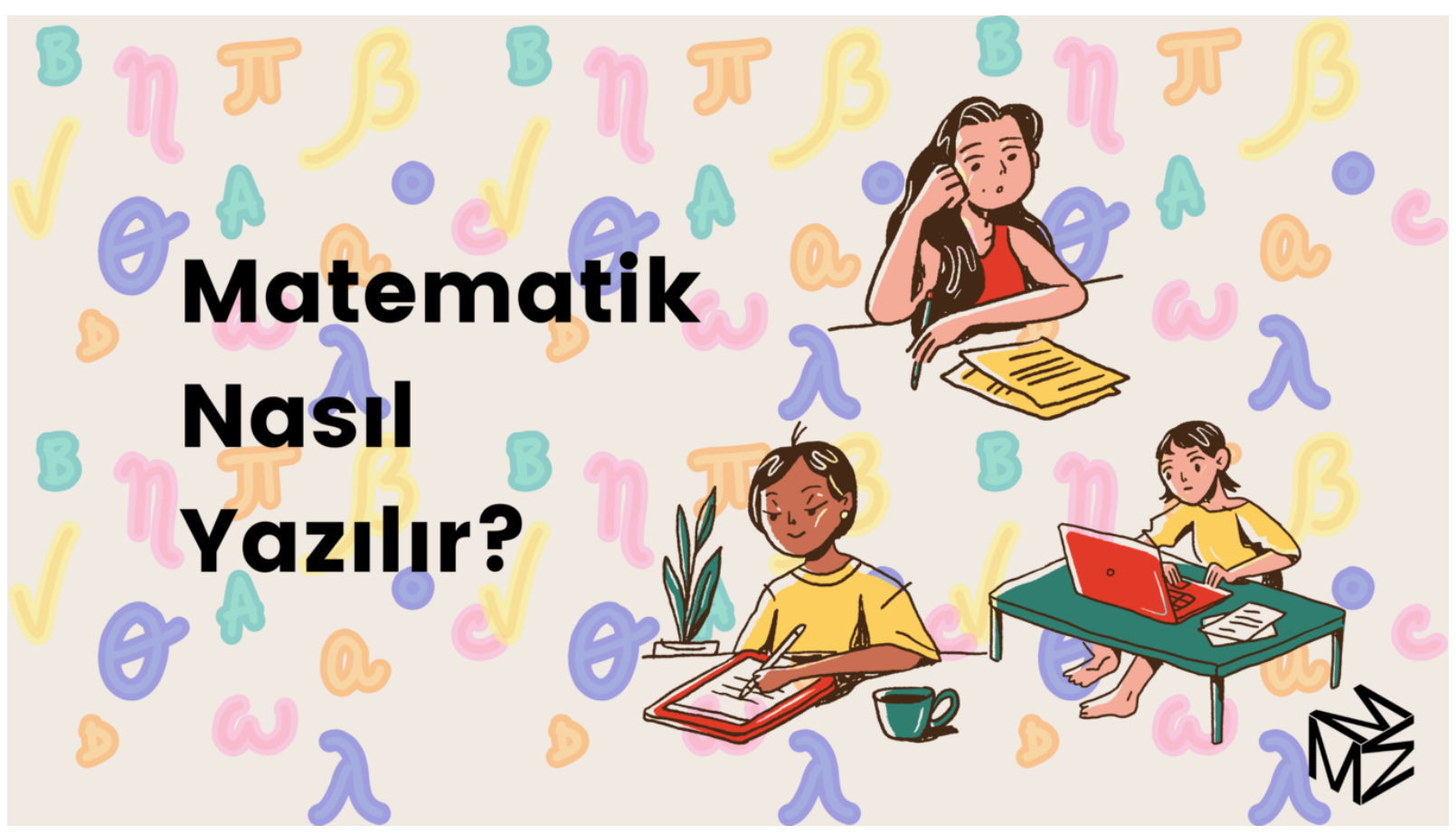

Figure 8: Matematik nasıl yazılır?

"We have a habit in writing articles published in scientific journals to make the work as finished as possible, to cover up all the tracks, to not worry about the blind alleys or describe how you had the wrong idea first, and so on."

"Bilimsel dergilerde yayınlanan makaleler yazarken çalışmayı olabildiğince bitmiş hale getirmek, tüm izleri örtmek, çıkmaz yollar hakkında endişe

Richard Feynman, Nobel Lecture, 1966.

Yazmak için birçok neden vardır. Bu nedenler ne olursa olsun etkin bir çalışma üretmek için pratik olmak gerekir. Yazmanızı nasıl iyileştireceğiniz üzerine yazılmış düşünceler toplamı aşağıda verilmiştir. Bir problemin yanıtını bulmakla onu sunmak arasındaki büyük fark kaydedilmelidir.

- Yalın, noktalamalı tümceler yazın.

- Yalınlığı koruyun.

- Ne yaptığınızı açıklayın.

- Savlarınızı açıklayın.

- Ne demek istediğinizi söyleyin ki hiçbir şey belirsiz kalmasın.

- Genellikle, sembollerden çok sözcükleri kullanın.

- Eşittir sembolünü doğru kullanın: Eşittir, eşittir demektir.

- Her yerde oklar çizmeyin: Denklemleri tanımak için semboller ya da sayılar kullanın.

- Ne yazdığınızı son bir kez okuyun.

- Derin düşünün, çalışmanıza yeni bir gözle bakın. 


\section{Bölüm: Matematiği Yazma II}

Bir önceki bölümde matematik yazmanın temel ilkeleriyle ilgilenmiştik. Bu bölümde daha kesin ve matematiğin sunumunu iyileştirmek için özel yöntemlere örnekler verilmiştir.

"Learn as much by writing as by reading."

"Okuyarak öğrendiğiniz kadar yazarak da öğrenin."

Lord Acton, Lectures on Modern History (1906)

- "Ĕ̆er" kelimesini kullanıyorsanız o zaman "o zaman" ifadesini kullanın.

- Her şey bir formül değildir. Şeyleri doğru isimleriyle adlandırın. Örneğin; $3 \mathrm{x}^{2}-7 \mathrm{x}$ bir ifadedir. $3 \mathrm{x}^{2}-7 \mathrm{x}$ $=5$ bir denklem ve $\mathrm{x}<=5$ bir eşitsizliktir.

- "O" sözcügünü kullanmayın.

- Kuramsal matematikte ondalık yaklaştırmalardan kaçının.

- Tümcelere bir sembolle başlamayın. ${ }^{3}$

- = gerektirme sembolünü doğru kullanın. Bu sembol eşittir işareti ile aynı işlevde kullanılmamalıdır. Doğru kullanım önerme = onerme'dir.

- Ortak sembolleri ve notasyonu kullanın ve onları önce tanımlayın.

- Bağlantılı tümcecik ve eş anlamlı sözcükleri kullanın.

3.Bu öğ̈̈t Türkçe yazmalarda geçerli değildir.

\section{Bölüm: Problemler Nasıl Çözülür}

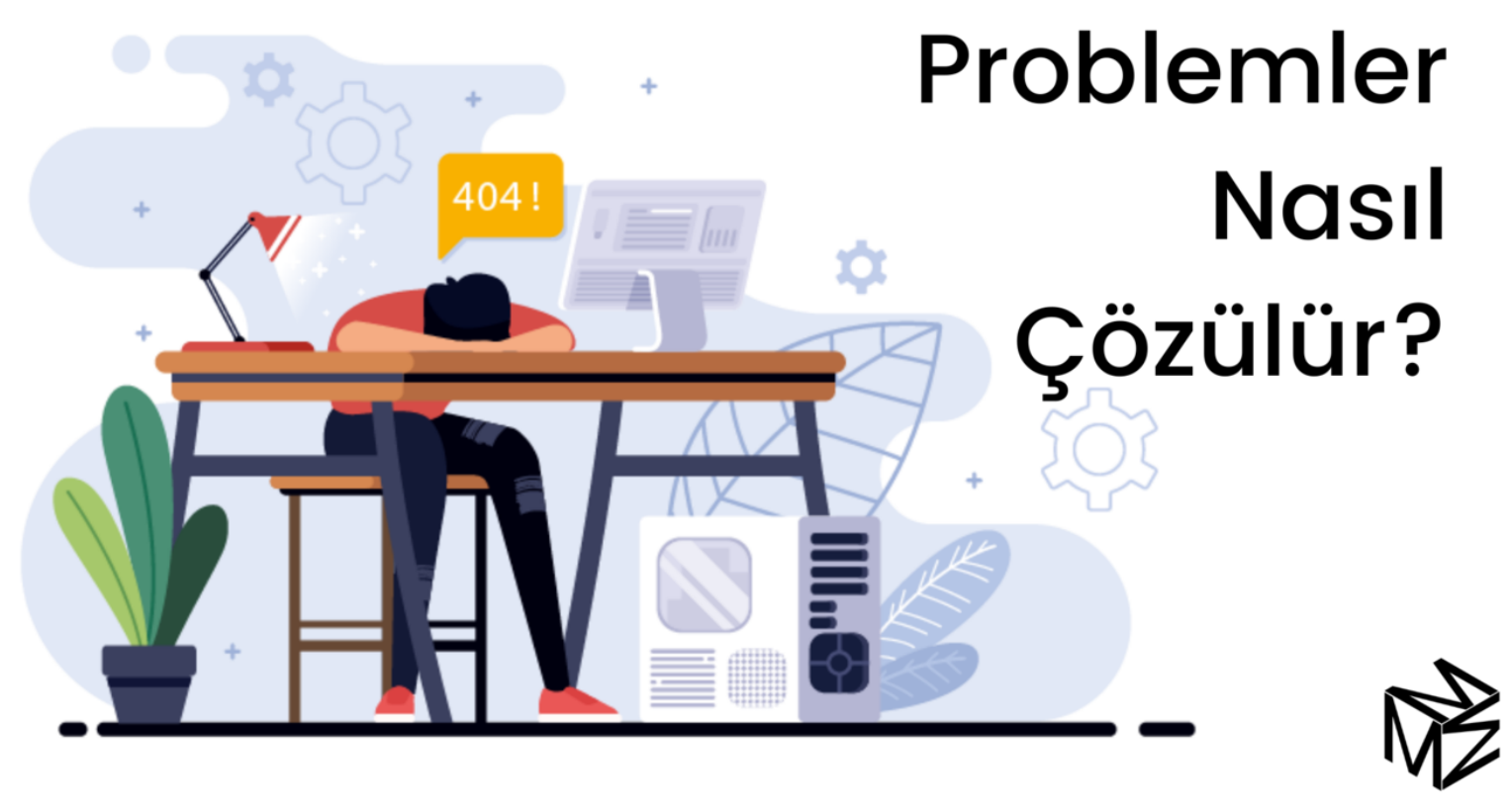

Figure 9: Polya'nın dört-adım planı problem çözümü için iyi bir yoldur. 
"It isn't that they can't see the solution. It is that they can't see the problem."

"Çözümü göremedikleri için değil. Problemi göremedikleri için."

\section{G.K. Chesterton, The Scandal of Father Brown - The Point of a Pin}

Problemlerin nasıl çözüldüğünü öğrenmenin en iyi yolu problem çözmektir, tecrübe önemlidir. Bunu söylememize rağmen problem çözerken uygulanabilecek yararlı uyarılar vardır. Polya'nın dört-adım planı bir problemi çözmek için iyi bir yoldur.

Polya'nın dört-adım planı ve matematikteki uygulamaları üzerine hazırladığımız yazımıza buradan ulaşabilirsiniz: \#Pergamon 001: Polya'nın Problem Çözme Algoritması

Matematikçi Gibi Düşünmek kitabının diğer bölümlerinin özetleri ilerleyen haftalarda \#Bibliotheca serimizle karşınızda olacak. Kitap ile ilgili yorumlarınızı sosyal medya hesaplarımızdan bizlerle paylaşmayı unutmayı!

Instagram: @mmmt_digital

LinkedIn: @mmmt-digital

Twitter: @mmmt_digital

Yazımıza atıfta bulunmak için aşă̆ıdaki gibi APA formatını kullanabilirsiniz:

MMMT. (2020, Kasım 20). \#Bibliotheca 002: Matematikçi Gibi Düşünmek I. Kısım: Matematikçiler İçin

Düşünme Becerileri - erişim tarihi - tarihinde,

www.authorea.com/494124/c-ppSekz4kHZSKr2C8ZDGg adresinden erişildi.

\section{Referanslar}

[1] Houston, K.(2009). How to Think Like a Mathematician. (Mehmet Terziler ve Tahsin Öner, Çev.).

Cambridge: Cambridge University Press. 